\title{
O BRINCAR COMO ELEMENTO DE INCLUSÃO ESCOLAR DE CRIANÇAS \\ CARACTERIZADAS COM TRANSTORNOS DO ESPECTRO AUTISTA (TEA)
}

\author{
THE PLAY AS SCHOOL INCLUSION OF CHILDREN ELEMENT CHARACTERIZED
}

\author{
WITH AUTISM SPECTRUM DISORDERS (ASD)
}

\author{
Maria Luzia da Silva Santana ${ }^{1}$ \\ Marcelo Máximo Purificação ${ }^{2}$ \\ Ana Paula Pertussati Teperino ${ }^{3}$ \\ Izabel Cristina Taceli ${ }^{4}$ \\ Maria Teresa Ribeiro Pessoa ${ }^{5}$
}

\begin{abstract}
Resumo
Esse estudo busca contribuir com o (re)visitar do ato de brincarão colocar como um dos recursos de inclusão escolar. Por isso, tem-se o objetivo de problematizar, principalmente, o brincar de crianças autistas como um dos elementos que pode ser constituinte de uma prática pedagógica inclusiva. A ação de brincar poderá funcionar como estimulador da interação social, imaginação, memória, atenção, linguagem, expressão de pensamentos, internalização de normas e regras sociais, em suma, constitui-se como um elemento da aprendizagem e do desenvolvimento da criança. A prática pedagógica direcionada às crianças com transtornos do espectro autista (TEA), quando utiliza o brincar, torna-se mais eficaz, favorecendo a interação infantil com os pares e sua inclusão no contexto educativo. Assim, o brincar surge como
\end{abstract}

\footnotetext{
${ }^{1}$ Doutoranda e Mestra em Psicologia (Universidade Católica de Brasília- UCB); Especialista em Educação e Promoção da Saúde (Universidade de Brasília - UNB) e em Psicologia Social (Universidade Estadual de Santa Cruz - UESC); Psicóloga (Centro de Ciências da Saúde da Universidade Federal do Recôncavo da BahiaUFRB); Licenciatura Plena em História (Universidade do Estado da Bahia/UNEB) e em Pedagogia (Faculdades Alfredo Nasser - UNIFAN). E-mail: maria-luzia.s.santana@ufms.br

${ }^{2}$ Pós-doutor pela Faculdade de Psicologia e Educação da Universidade de Coimbra (2015). Doutor em Ciências da Religião (Sub área CNPq Teologia/Filosofia) pela Pontifícia Universidade Católica de Goiás (2014 - Conceito 5 na CAPES). Mestre em Educação Comunitária - Infância e Juventude FEST/UFRGS (2009 - Conceito 6 na CAPES). Mestre em Ciências Educacional - UEP (2007). E-mail: maximo@fimes.edu.br

${ }^{3}$ Formada em Psicologia pela Universidade FUMEC/MG em 2001. Pós graduada em Neuropsicologia pela mesma Universidade em 2006. Mestre em Psicologia pela UCB de Brasília em 2014. E-mail: anapertussati@gmail.com

${ }^{4}$ Doutoranda em Serviço Social pela Universidade Estadual Paulista Júlio de Mesquita Filho, UNESP/Franca SP (2014); Mestre em Psicologia - Linha de Pesquisa em Saúde Mental e Ações Terapêuticas pela Universidade Católica de Brasília (12/14). Docente em Cursos de Graduação na Universidade do Estado de Minas Gerais UEMG - Unidade Frutal - MG nos Cursos de Administração, Comunicação Social, Direito e Geografia (04/15) e Cursos de Pós-Graduação no Instituto de Educação Continuada - ITECON - Frutal - MG (00/15) e na UniFil Centro Universitário Filadélfia - Londrina/Paraná. Consultora de Projetos pela Fundação Centro Internacional de Capacitação, Educação e Pesquisa Aplicada em Águas - UNESCO/HidroEX (14/15). E-mail: itaceli@hotmail.com

${ }^{5}$ Professora Associada da Faculdade de Psicologia e de Ciências Educação da Universidade de Coimbra. Tem desenvolvido trabalho como docente nas áreas da formação de professores e da utilização pedagógica das tecnologias e lecionado, a nível nacional e internacional, em mestrados e doutoramentos nestas mesmas áreas. Assim lecionou diversos temas (Formação Narrativa de Professores, Tecnologia Educativa, Teoria da Educação, Conceção e Produção de Materiais Educacionais, Teorias e Modelos de Formação Professores, Inovação Pedagógica) em várias Universidades Portuguesas (Lisboa, Porto, Braga, Coimbra) em Universidades Brasileiras (Paraná, Piauí, Rio Grande do Norte, Rio de Janeiro) e em Espanha (Universidade Autónoma de Madrid, Universidade de Granada, Universidade de Málaga Universidade de Salamanca) e Universidade Karlova de Praga. E-mail: tpessoa@fpce.uc.pt
} 
elemento possibilitador da aprendizagem e do desenvolvimento de crianças nos espaços formais de educação que merece atenção, principalmente quando se pensa no processo inclusivo de estudantes autistas.

Palavras-chave: Autismo. Brincar. Crianças. Práticas Pedagógicas Inclusivas.

\begin{abstract}
This study seeks to contribute to the (re) visiting the act of playing the place as one of the school inclusion resources. So, has the aim of questioning, especially the play of autistic children as one of the elements that can be a constituent of an inclusive classroom. The action of play can function as stimulating social interaction, imagination, memory, attention, language, expression of thoughts, internalization of social norms and rules, in short, is constituted as a learning and development of the child element. The pedagogical practice directed to children with autism spectrum disorders (ASD), when you use the play becomes more effective, promoting child interaction with peers and their inclusion in the educational context. Thus, the play emerges as an enabler element of learning and development of children in formal education spaces that deserves attention, especially when one thinks of the inclusive process of autistic students.
\end{abstract}

Keywords: Autism. Children. Play. Pedagogical Practices Inclusive.

\title{
INTRODUÇÃO
}

Atualmente, falar de crianças em processo de inclusão, principalmente sobre aquelas que têm demandas singulares de comunicação e interação social, é colocar em diálogo preconceitos ainda presentes na sociedade. Imperativo da cultura de segregação, conforme apontam Ciantelli, Leite e Martins (2014), a pessoa com deficiência era vista como um louco, doente e incapaz. Sobre essa questão Carvalho (2010) aponta que no modelo clínico algumas alterações orgânicas (estruturais ou funcionais) são tidas estatisticamente como desviantes.

Socialmente, as pessoas com essas alterações são vistas como doentes e incapazes, o que leva a confundira deficiência com patologias, e as barreiras que delas decorrem (como não enxergar, não ouvir, não andar, por exemplo), como empecilhos para uma vida considerada normal dentro dos padrões sociais preestabelecidos (CARVALHO, 2010).Essa ideologia da normalização foi base da educação especial. O termo educação especial "andou muito tempo colado às crianças em situação de deficiência, tendo as várias categorias de deficiência sido substituídas pelo termo genérico de necessidades educativas especiais ou específicas" (SANCHES; TEODORO, 2006, p.67). Até mesmo na contemporaneidade, quando se tem um discurso de inclusão e respeito à diversidade como elementos de garantias dos direitos humanos, observam-se práticas pedagógicas distanciadas dessa base.Com vistas 
na prática pedagógica inclusiva, direcionada aos alunos com "singularidades reais/visíveis"6; e com o intuito de contribuir coma criação de recursos adequados, bem como de melhorar as condições de inclusão de crianças com as características dos critérios diagnósticos dos transtornos do espectro autista, tem-se o objetivo de problematizar o brincar no cotidiano dessa população,como um dos elementos que pode ser constituinte de uma prática pedagógica inclusiva.

Para atender a esse objetivo realizou-se um levantamento bibliográfico sobre as práticas pedagógicas inclusivas direcionadas às crianças com autismo e as suas brincadeiras. A análise do material encontrado possibilitou a elaboração desse artigo que endereça algumas contribuições para o trabalho docente e a inclusão escolar, porém sem pretensão de esgotá-las. Considerando uma leitura histórica, social e cultural da deficiência, mas sem negar as questões orgânicas tendo "o natural e o cultural" " como ponto de partida nessa discussão, elucidou o ato de brincar de crianças com autismo como um dos recursos de inclusão escolar.

\section{DILEMAS E PERCURSOS DA EDUCAÇÃO INCLUSIVA}

Observa-se que nas escolas e classes especiais perpassava a ideia de que pertencia à criança a responsabilidade de se adaptar às exigências do contexto social, ou seja,“[...] as pessoas eram deficientes por causas fundamentalmente orgânicas, que se produziam no início do desenvolvimento e cuja modificação posterior era difícil” (MARCHESI, 2010, p. 15). Quanto às terminologias, Carvalho (2010) registra a modificação das expressões "excepcional", "deficiente", "portador de deficiência", "pessoa com deficiência” e outros, pelo termo "necessidades especiais", justificando um intuito persuasivo dos "especialistas" em relação aos "leigos".

Essa discussão acerca do termo ou expressão a ser utilizada tem a finalidade de contribuir, através de palavras, com um corte epistemológico que evolua do paradigma reducionista organicista - que focaliza a deficiência da pessoa - para o paradigma interacionista - que requer uma compreensão dialética da relação sujeito/mundo.Numa leitura interacionista, "necessidades especiais"demonstram as exigências experimentadas por qualquer pessoa e que necessitam ser supridas pela sociedade. Enquanto a expressão "pessoa portadora de deficiência" põe em destaque a pessoa que "carrega" (porta, possui) uma

${ }^{6}$ Os autores desse artigo adotaram a expressão "singularidades reais/visíveis" para se reportar a estudantes com necessidades educacionais especiais.

${ }^{7}$ Para maiores esclarecimentos sobre essa expressão consultar Vigotski (2011, p. 866). 
deficiência, deseja-se que a expressão "necessidades especiais" apele para a responsabilidade social. (CARVALHO, 2010).

Numa perspectiva histórica, percebe-se que o diálogo em torno da inclusão educativa é marcado por embates e dilemas sobre as práticas excludentes nos contextos educativos. Resultado de um processo histórico marcado por movimentos sociais, a discussão a respeito da garantia dos direitos das "pessoas de singularidade concreta/visível", iniciada com a institucionalização de escolas especiais, ainda está em curso. Por outro lado, não se nega a preocupação das escolas especiais com o "ensino das crianças em situação de deficiência e das que, por outras razões, também se viam excluídas, formal ou informalmente, do sistema de ensino". (SANCHES; TEODORO, 2006, p.67-8).

A expressão "pessoa de singularidade concreta/visível” é adotada no decorrer do presente escrito para se reportar às pessoas com deficiência. Não se nega as peculiaridades no seu aparato biológico, porém,manifesta também a ideia de que há uma visibilidade mais expressiva e explícita dessas peculiaridades, que foram evidenciadas nos contextos, como por exemplo da paraplegia, da surdez, da cegueira, e outras inúmeras denominações dadas pela ciência. Assim, a "falta", a "deficiência" posto como substantivo ${ }^{8}$ que as sujeita e toma a visibilidade do humano na sua integralidade é problematizada com o intuito de colocar na contramão a ideologia ainda dominante em determinados contextos.

Assim, a pessoa com deficiência era deixada distante do convívio social para desumanizá-lo e excluí-lo das relações sociais e humanas. Essas ideias inatistas dominantes no circuito científico contribuíram para biologizar e normatizar os seres humanos dotados de subjetividade e singularidade. A deficiência é percebida a partir do viés quantitativo de ausência, como um defeito, uma falha e um empecilho para o desenvolvimento linear esperado. Essa leitura do desenvolvimento humano numa visão determinista, acrítica e ahistórica presentes nas escolas especiais direcionadas às pessoas com deficiência, ainda são desafios reais e atuais.

Mesmo se observando uma busca de rompimento com as etiquetas validadas pelos laudos e diagnósticos médicos de crianças, a ideia de que é um sujeito incompleto permaneceu como status determinante na gestão administrativa, nos discursos e práticas dos docentes. Sanches e Teodoro (2006) assinalaram que a integração escolarnos países que a

\footnotetext{
${ }^{8}$ Para não utilizar o termo sujeito, a expressão "substantivo" foi usada coma finalidade de expressar a substância, a essência, a própria pessoa.
} 
implantaram, e o uso de seu conceito possibilitou a constituição de um subsistema de educação especial dentro das escolas regulares para alunos com necessidades educativas especiais e seus professores. Não houve uma modificação ou adaptação do sistema de ensino diante dessa realidade; ao contrário, os alunos e os professores é que foram obrigados afazer o possível e o impossível para se adequar às regras e ao seu funcionamento, para ter direito a um espaço no meio escolar normal, enquanto o sistema não se questionava nem preconizava qual quer transformação.

Como lembra Marchesi (2010) o movimento da integração não deveria ser somente a transferência dos alunos da educação especial para as escolas regulares, junto com seus professores, recursos materiais e técnicas. A insatisfação com as interpretações parciais da integração foi o que levou à modificação da terminologia e a proposição de que o principal objetivo das mudanças fosse "educar" os estudantes com necessidades educacionais especiais e não apenas permitir que eles fossem aceitos em salas regulares, sem nenhum preparo para isso.

As escolas integradoras implicariam, assim, numa pedagogia voltada para o aluno, para identificar e suprir suas necessidades com o intuito de possibilitar o seu pleno desenvolvimento e - em respeito aos seus direitos de cidadania - de pertencer e de participar. "Nessas escolas integradoras, os alunos com necessidades educacionais especiais devem, sempre que possível, aprender junto com seus pares, ditos normais, para fomentar a solidariedade entre todos". (CARVALHO, 2010, p. 46).

A definição de necessidades educacionais especiais remete à provisão de recursos educativos indispensáveis para atender as necessidades e diminuir as dificuldades de aprendizagem que os estudantes apresentam. Os recursos educativos podem ser muito diversos, incluindo professores capacitados, materiais didáticos específicos para esses alunos e possibilidade de acesso ao currículo (MARCHESI, 2010). Assim, a educação especial, a partir do seu processo histórico, pode ser entendida como:

[...] um conjunto de meios postos ao serviço das crianças e jovens com Necessidades educativas especiais para que eles tenham acesso às aprendizagens. Outros profissionais, outros métodos (nem sempre), outras matérias para aprender (mais curtas, menos exigentes), outros espaços, dentro da escola, mas a maior parte das vezes fora da sala de aula à qual, por direito, pertencem. Uma Educação especial para alunos especiais. (SANCHES; TEODORO, 2006, p. 69). 
O enfoque da integração foi considerado insuficiente e limitado por não considerar os alunos que precisavam de uma resposta educativa individualizada. Contudo, não se pode negar que, no contexto histórico-cultural no qual ocorreu a integração, esse movimento possibilitou a constituição de propostas mais radicais articuladas em torno de um movimento por uma educação e uma escola inclusiva, com a exigência de educar todos os estudantes numa mesma escola e a necessidade de realizar uma reforma do conjunto do sistema educacional. (MARCHESI, 2010).

A experiência adquirida com a integração escolar e toda a reflexão que a mesma gerou sobre a escola que exclui uma parte considerável dos seus alunos, não somente os que se encontram em situação de deficiência, ajudou a desencadear o movimento da inclusão que pretende promover o sucesso pessoal e acadêmico de todos os alunos, numa escola inclusiva. (SANCHES; TEODORO, 2006, p. 69).

Nessa perspectiva, foi colocada em destaque a educação com vistas nas peculiaridades e singularidades de todos, independentemente da pessoa ter uma "singularidade concreta/visível". Assim, um dos maiores desafios da atualidade se constitui na realização de uma ação pedagógica eficaz e centrada no sujeito que, de fato, seja condizente com as prerrogativas político-sociais da Declaração de Salamanca (1996), que estabelece que as escolas necessitam acomodar todas as crianças, independentemente de suas condições físicas, intelectuais, sociais, emocionais, linguísticas, étnicas ou culturais. Esses pressupostos geram inúmeros e diferentes desafios aos sistemas escolares.

Comungando das ideias de Sanches e Teodoro (2006), no contexto escolar poderá existir uma prática educativa inclusiva, numa educação em que a diversidade do grupo não seja vista como mais um problema e sim um grande desafio à criatividade e ao profissionalismo dos educadores, suscitando e conduzindo as mudanças de hábitos e comportamentos, de políticas e de ações educativas na prática dos educadores. Cunha (2012) salienta que não é possível falar em inclusão sem referir ao papel do professor. Assim, sugerese que o professor direcione sua prática com vistas no paradigma da inclusão e da diversidade.

Vigotski (1989),nos estudos sobre a defectologia, discutiu a respeito das deficiências,apontando que o meio social influencia a maneira como o sujeito compreende o seu defeito orgânico e sua relação com a instituída deficiência.Ou seja, conforme os pressupostos vigotskianos, há a deficiência primária - que diz respeito mais aos aspectos de ordem orgânica - e a deficiência secundária, que inclui os empecilhos de caráter social. 
Nesse sentido, "as consequências sociais do defeito acentuam, alimentam e consolidam o próprio defeito. Neste problema não existe aspecto algum onde o biológico pode ser separado pelo social" (VIGOTSKI, 1989, p. 93).O mesmo autor não nega as implicações da deficiência na criança, esclarecendo que:

Por um lado, ele é uma deficiência e atua diretamente como tal, produzindo falhas, obstáculos, dificuldades na adaptação da criança. Por outro lado, exatamente porque o defeito produz obstáculos e dificuldades no desenvolvimento e rompe o equilíbrio normal, ele serve de estímulo ao desenvolvimento de caminhos alternativos de adaptação, indiretos, os quais substituem ou superpõem funções que buscam compensar a deficiência e conduzir todo o sistema de equilíbrio rompido a uma nova ordem. (VIGOTSKI, 2011, p.869).

A defectologia vigotskiana reavalia, de maneira radical, a visão contemporânea da educação, ao pontuar que o olhar tradicional considera o defeito nos seus aspectos negativos, ou seja, focaliza o menos, a falha, a deficiência pelo ângulo da perda das funções do desenvolvimento da criança. Assim, a psicologia da criança atípica foi vista pelo método da subtração das funções perdidas em relação à psicologia da criança com desenvolvimento normal. (VIGOTSKI, 2011).

$\mathrm{Na}$ perspectiva vigotskiana, a dinâmica do desenvolvimento da criança com deficiência é pensada para além da via biológica,“o desenvolvimento cultural é a principal esfera em que é possível compensar a deficiência. Quando não é possível avançar no desenvolvimento orgânico, abre-se um caminho sem limites para o desenvolvimento cultural" (VIGOTSKI, 2011, p.869).Tais pressupostos colocam em cheque a ideia da impossibilidade de inclusão de alunos com "singularidade concreta/visível".

É também um convite para os profissionais da educação que ainda se encontram na zona de conforto, que olham a criança pelo prisma do defeito, repensar suas práticas a fim de atendê-la a partir de suas necessidades e singularidades, principalmente aquelas que estão em processo de inclusão nas salas regulares de ensino. Por outro lado, não se nega a necessidade de melhorias e avanços na formação inicial e continuada de professores para lidar de maneira crítica, com o desafio de incluir sem excluir e assegurar a todas as crianças, a sua inserção no grupo, na comunidade, na cultura e na educação escolar.

Apesar disso, o paradigma da inclusão no contexto brasileiro ${ }^{9}$ tem impulsionado mecanismos voltados para a garantia do direito de todos. No que se refere ao acesso das

${ }^{9}$ Informações históricas e legais sobre o processo de inclusão no contexto brasileiro estão disponíveis no site da Secretaria de Educação Continuada, Alfabetização, Diversidade e Inclusão (SECADI). Com o objetivo de 
pessoas com "singularidades concretas/visíveis" à educação inclusiva, encontram-se em curso leis, normas, decretos e projetos de mudanças nas políticas públicas, assim;

[...] a educação inclusiva torna-se pauta constante nos debates educacionais brasileiros, impulsionando novas formulações que reorientam o apoio técnico e financeiro, no sentido de prover as condições para a inclusão escolar dos estudantes público-alvo da educação especial nas redes públicas de ensino. Assim, o conceito de acessibilidade é incorporado como forma de promoção da igualdade de condições entre todos. (BRASIL, 2015, p.13).

A igualdade nas condições de acesso à escolarização das crianças e adolescentes que; a partir das características especificadas no Manual Diagnóstico e Estatístico de Transtornos Mentais (DSM-V); são caracterizadas com os transtornos do espectro autista, é assegurada nas políticas públicas de inclusão brasileira. Conforme Guareschi, Alves e Naujorks (2014), a inclusão de alunos nessa condição teve maior atenção após a promulgação da Política Nacional de Educação Especial na Perspectiva da Educação Inclusiva em 2008.

A partir dessa política, os dispositivos legais passaram a tratar mais especificamente da inclusão escolar desses alunos que até então não eram mencionados de maneira clara nos textos legais e demais publicações. Com base no DSM-V o autismo é visto como deficiência e a SECADI assegura que o trabalho pedagógico com crianças autistas deve ser desenvolvido nas instituições escolares. (GUARESCHI; ALVES; NAUJORKS, 2014).

\section{A PRÁtiCA DOCENTE E O BRINCAR DE CRIANÇAS COM CARACTERÍSTICAS DOS TRANSTORNOS DO ESPECTRO AUTISTA}

As crianças autistas têm o direito a acessibilidade e inclusão nos espaços escolares. Contudo, é necessário que todos - principalmente os órgãos institucionais de promoção e de defesa, a família e aos profissionais da educação - contribuam para implementar e assegurar esse direito, sendo que tais esforços contribuirão com a apropriação das ferramentas culturais e inserção social desses alunos.

As influências sociais e culturais no desenvolvimento da criança foram apontadas por Vigotski (2011) em vários estudos. Nos seus estudos sobre defectologia, a deficiência foi

contribuir para o desenvolvimento inclusivo dos sistemas de ensino, voltados à valorização das diferenças e da diversidade, à promoção da educação inclusiva, dos direitos humanos e da sustentabilidade socioambiental, visando à efetivação de políticas públicas transversais e intersetoriais, esse órgão - articulado aos sistemas de ensino - implementa políticas educacionais nas diversas áreas, dentre elas a de educação em direitos humanos, educação especial, do campo, escolar indígena, quilombola e educação para as relações étnico-raciais.

Os programas, as ações, as publicações e legislação da SECADI estão disponíveis em: $<$ http://portal.mec.gov.br/secretaria-de-educacao-continuada-alfabetizacao-diversidade-e-inclusao $>$. 
vista para além das causas orgânicas, incluindo as questões sociais e culturais. A partir desse viés vigotskiano, as crianças que têm o curso de desenvolvimento diferenciado, a exemplo dos autistas, demandam uma reorganização no seu meio social para atender as suas necessidades.

A inserção e interação de alunos autistas no contexto socioeducativo, sobretudo, em processo de inclusão escolar pressupõe que o professor compreenda o percurso histórico e os critérios de diagnósticos utilizados pelos órgãos oficias para definir esse transtorno. A dificuldade quanto à nomeação e definição do autismo nos últimos anos demonstrou uma ausência de consenso quanto às particularidades sobre quem é esse sujeito e como ele aprende, e, consequentemente, ocasionou implicações na garantia de seus direitos. (GUARESCHI; ALVES; NAUJORKS, 2014).

O autismo foi primeiramente definido numa descrição dada por Leo Kanner, em 1943, que caracterizou o isolamento autista como um distúrbio inato e relatou casos de onze crianças que apresentavam em comum um isolamento extremo desde o começo da vida e um anseio obsessivo pela preservação da rotina, às quais chamou de autistas (MARINHO; MERKLE, 2009). A criança com a síndrome do espectro autista tem dificuldade em se relacionar com outros indivíduos, mantém-se distante, evita o contato visual e demonstra falta de interesse pelas pessoas, e dificuldade de comunicação, que afeta a compreensão e a expressão. (PIAUILINO, 2008).

Os transtornos do espectro autista são caracterizados pelos déficits clinicamente significativos e persistentes na comunicação social e nas interações sociais.O autismo manifesta-se antes dos três anos e persiste durante a vida adulta, com mais frequência em meninos (APA, 2014). Inicialmente, pode ser definido como um complexo distúrbio de desenvolvimento que envolve dificuldades de interação social, linguagem, plano emocional, plano motor e as áreas de habilidades sensoriais. (PIAUILINO, 2008).

No entanto, muitas crianças com o desenvolvimento típico gostam de repetição, por isso, em pré-escolares pode ser difícil apontar padrões restritos e repetitivos de comportamentos de crianças com o transtorno do espectro autista. No ambiente familiar, a persistência em rotinas e a aversão à mudança, assim como as sensibilidades sensoriais podem interferir na alimentação e no sono, tornando os cuidados de rotina extremamente difíceis. As dificuldades para planejar, organizar e enfrentar a transformação podem trazer impacto negativo na aprendizagem e, consequentemente, no sucesso acadêmico. (APA, 2014). 
Os critérios para diagnósticos dos transtornos do espectro autista incluem déficits persistentes na comunicação social e na interação social em diversos contextos, incluindo déficits na reciprocidade sócioemocional, na comunicação, no desenvolvimento, na manutenção e compreensão de relacionamentos. Além disso, incluem padrões restritos e repetitivos de comportamento, interesses ou atividades motoras, uso de objetos ou fala estereotipada ou repetitiva com insistência nas mesmas coisas, adesão inflexível a rotinas ou padrões ritualizados na ação verbal ou não verbal; interesses fixos e altamente restritos que são anormais em intensidade ou foco; hiper ou hiporreatividade a estímulos sensoriais ou interesse incomum por aspectos sensoriais do ambiente. (APA, 2014).

Para que o diagnóstico se confirme, os sintomas necessitam estar presentes precocemente na fase do desenvolvimento, causar prejuízo clinicamente significativo no funcionamento social, profissional ou em outras áreas relevantes da vida da pessoa.Essas dificuldades não podem ser compreendidas mediante a deficiência intelectual ou atraso global do desenvolvimento. As manifestações de prejuízos sociais e de comunicação e comportamentos restritos/repetitivos que caracterizam os transtornos do espectro autista prejudicam a aprendizagem da criança. (APA, 2014).

Conforme aponta Guareschi, Alves e Naujorks (2014) a utilização da terminologia autista nos dispositivos legais e documentos orientadores do Ministério da Educação, possibilita pensar as particularidades da escolarização dessas crianças, aspecto dificultado quando se usava a especificação mais abrangente das condutas típicas.A partir de um olhar mais apurado dos críticos de diagnósticos considerados pelo DSM- V, a educação da população autista deve ser pensada considerando seu processo próprio de desenvolvimento, devendo ser evidenciadas as habilidades e capacidades de aprendizagem e desenvolvimento que a criança tem, e não apenas suas limitações. A criança autista, mesmo tendo as vias de seu desenvolvimento fora do esperado, poderá ser mediada em sua comunicação, sua interação social e seu processo de aprendizagem e desenvolvimento.

Para isso, é necessário ultrapassar a barreira da acessibilidade, que aqui envolvem as práticas pedagógicas pautadas nas teorias científicas, extremamente inatistas e ambientalistas, unificadoras e distantes da diversidade humana. $\mathrm{Na}$ garantia dos direitos das pessoas com autismo, é fundamental que a família, os amigos, os profissionais da educação busquem entendê-los em sua forma de ser, possibilitando-lhes sua inserção no contexto social e cultural. Essa ação requer que o professor realize investimentos em metodologias e recursos 
adequados para, minimamente, facilitar e possibilitar um espaço rico de oportunidades para a interação social da criança e do adolescente com transtorno do espectro autista com os colegas. Cunha (2007), Fiaes (2010), Daguano e Fantacini, (2011), Martins e Góes (2013), dentre outros, têm ressaltado a possibilidade de trabalhara inclusão e a aprendizagem dessas crianças através da brincadeira.

\subsection{O brincar como elemento de inclusão de crianças autistas no contexto educativo}

Vigotsky (1984) considerou que o desenvolvimento e o funcionamento do cérebro humano estão intimamente relacionados ao contexto sócio-histórico e cultural. Assim, as funções psicológicas humanas são construídas no decorrer das relações e interações do sujeito.Nesse sentido, a brincadeira, especificamente a de faz-de-conta, é uma atividade que cria uma Zona de Desenvolvimento Proximal (ZDP). A ZDP é compreendida como:

[...] a distância entre o nível de desenvolvimento real, que se costuma determinar através da solução independente de problemas, e o nível de desenvolvimento potencial, determinado através da solução de problemas sob a orientação de um adulto ou em colaboração com os companheiros mais capazes. (VIGOTSKY, 1984, p. 97).

Aquilo que a criança tem potencial para realizar, Vigotsky $(1984$, p. 97) considerou funções que “poderiam ser chamadas de 'brotos' ou 'flores' do desenvolvimento, ao invés de 'frutos' do desenvolvimento". Assim, caracterizou o nível de desenvolvimento real numa perspectiva retrospectiva, enquanto a ZDP a partir de um olhar prospectivo.

$\mathrm{O}$ ato de brincar pode ser visto com o olhar prospectivo que possibilita o aprendizado situar-se à frente do desenvolvimento da criança, quando ela realiza ações que estão além do que sua idade lhe permite realizar, mas que tem potencialidade para realizá-las. A brincadeira,por ser uma atividade social,é influenciada pelo contexto histórico, cultural e social. Para Vigotsky (1984) a brincadeira e o jogo são atividades específicas da infância, nas quais a criança recria a realidade usando sistemas simbólicos.

O brinquedo provê, assim, uma situação de transição entre a ação da criança com objetos concretos e suas ações com significados. "Mas, além de ser uma situação imaginária, o brinquedo é também uma atividade rígida por regras. Mesmo no universo de faz-de-conta há regras que devem ser seguidas" [...] (OLIVEIRA, 1993, p.67).A brincadeira favorece a socialização, mediante o contato com outras crianças presentes na escola, na comunidade, em casa e outros locais que elas frequentam. 
Através do brincar, a criança desenvolve a capacidade de criar, imaginar, cooperar, seguir regras, desenvolver a autoestima, autoconfiança e o seu eu. $\mathrm{Na}$ brincadeira tem-se a estimulação da inteligência, o exercício das habilidades atencionais, o engajamento e o desempenho de papéis avançados.

São justamente as regras da brincadeira que fazem com que a criança se comporte de forma mais avançada do que daquela habitual para sua idade [...] O que na vida real é natural e passa despercebido, na brincadeira torna-se regra e contribui para que a criança entenda o universo particular dos diversos papéis que desempenham. Tanto pela criação da situação imaginária, como pelas definições de regras específicas, o brinquedo cria zona de desenvolvimento proximal na criança. No brinquedo a criança se comporta de forma mais avançada do que nas atividades da vida real e também aprende a separar objeto de significado. (OLIVEIRA, 1993, p. 67).

Destarte, o jogo e o brincar têm muito a contribuir com as atividades pedagógicas no decorrer das aulas. A realização de atividades que possibilitam o envolvimento da criança em brincadeiras, principalmente aquelas que auxiliam na criação de situações imaginárias, tem visível função pedagógica. $\mathrm{O}$ contexto escolar, e particularmente os profissionais que atuam na pré-escola podem fazer uso de maneira deliberada dessas situações para atuar no processo de desenvolvimento das crianças. (OLIVEIRA, 1993).

As atividades que envolvem jogos e brincadeiras podem criar zonas de desenvolvimento para as crianças com necessidades educacionais especiais, incluindo as que têm o transtorno do espectro autista. Apesar dos benefícios que a brincadeira proporciona, como aponta Fiaes (2010), no Brasil estudos sobre a brincadeira de crianças com o transtorno do espectro autista são ainda iniciais, faltando uma maior compreensão das características que são típicas da cultura e que podem influir de alguma maneira na demonstração da brincadeira.

O estudo realizado por Martins e Góes (2013) ajuda na discussão desta temática, já que para eles o brincar de crianças autistas é relatado de maneira limitada e peculiar. Sobre essa situação, Silva, Dias, Martins e Tenório (2011) apontam que é necessário realizar uma ponte entre a criança autista, a sociedade e o mundo. Quanto a isso, o educador poderá estabelecer vínculo com a criança autista, conseguir dela um contato visual e contribuir com a sua inserção, interação e envolvimento nas atividades e brincadeiras.

As brincadeiras e os jogos - quando presentes no cotidiano da criança - fazem com que a aprendizagem seja mais descontraída e eficiente, contribuindo para o seu desenvolvimento e o aperfeiçoamento de habilidades físicas, intelectuais, visuais, auditivas e morais (DAGUANO; FANTACINI, 2011). Através do ato de brincar a criança assimila valores, adquire comportamentos, desenvolve diversas áreas de conhecimento, exercita-se fisicamente 
e aprimora as demais habilidades. A partir das ideias de Vigotsky (1984), observa-se que a criança, ao brincar, poderá internalizar regras e normas sociais, aprende a dar e receber ordens, a esperar sua vez, a emprestar e tomar o brinquedo emprestado, resultando em uma criança que desenvolve a sociabilidade.

Cunha (2007) ressalta que, no brincar, a criança conhece e coloca em prática seus pontos positivos, além de aprender a considerar as diferenças que existem de uma pessoa para outra. Os brinquedos são parceiros silenciosos que desafiam a criança possibilitando descobertas e estimulando sua autoexpressão. É preciso haver tempo para eles, e espaço que assegure a tranqüilidade suficiente para que a criança brinque e solte a sua imaginação, inventando, sem medo de desgostar alguém ou de ser punida, onde possa, apenas, brincar. (CUNHA, 2007).

O respeito ao ritmo da criança colabora com a prática e o significado das escolas inclusivas como:

[...] um processo de mudança que conduz progressivamente a uma participação maior dos alunos na cultura e no currículo comum da escola. Esse processo de mudanças deve tornar possíveis as transformações no funcionamento da escola e na prática educativa na sala de aula que permitam aos alunos com necessidades educativas especiais ter acesso ao currículo em um ambiente integrador. (MARCHESI, 2010, p. 29).

A depender da iniciativa e sensibilidade das pessoas que interagem com a criança autista no contexto escolar, o ato de brincar poderá ser elemento favorecedor do seu desenvolvimento global. Quanto a isto, Silva, Dias, Martins e Tenório (2013) apontam que o brincar é uma ótima maneira para estimular a interação de crianças autistas com o mundo, favorecendo o contato com a vida em sociedade. Os autores salientam que a evolução desses alunos acontece em tempos diferenciados, já que cada aluno autista apresenta uma particularidade que exige do docente uma maior preparação para atendê-los.

Por esse ângulo, Lima e Fumes (2013) asseguram que é necessário proporcionar às crianças com autismo a oportunidade de brincar. E observaram que as crianças tiveram boa evolução com o uso dos brinquedos, em particular no decorrer dos jogos com bola, porém algumas delas avançaram para brincadeiras que exigem uma complexidade maior, participando também nos momentos de brincadeiras da "peteca", do jogo de tênis infantil e do boliche. Além disso, esses autores aconselharam que as brincadeiras sem o uso de brinquedos fossem mais incentivadas e desenvolvidas entre essas crianças. 
No estudo desenvolvido por Martins e Góes (2013), com a mediação dessas pesquisadoras durante a brincadeira, as crianças autistas apresentaram ações imaginativas e em diversos momentos chegaram a se envolver no jogo de papéis. Apesar das ações imaginativas terem uma característica incipiente e pouco frequente no decorrer das sessões, o seu valor não deve ser subestimado, tendo em vista que o mais relevante é o fato de os sujeitos se mostrarem responsivos ao encorajamento do adulto no sentido de melhorar suas capacidades, constituindo avanços numa área essencial ao desenvolvimento na infância.

Há indícios, entretanto, que as práticas educativas que podem incentivar as interações sociais e o desenvolvimento de crianças autistas não estão presentes no contexto escolar. Corroborando com essa ideia a pesquisa de Minatel e Matsukura (2015), com o objetivo de identificar sob a ótica de famílias de crianças e adolescentes com autismo, as experiências no contexto escolar vivenciadas por eles junto a escolas regulares e especiais, apontaram dificuldades e desafios enfrentados pelos familiares. Os resultados sinalizaram que as preocupações das famílias voltam-se a aspectos do cuidado, aceitação e respeito a seus filhos. Além disso, as famílias vivenciaram um cotidiano atravessado por dificuldades e preocupações no processo de inclusão escolar, no que se refere aos direitos, aos cuidados e ao preparo da instituição escolar em receber essa população, com destaque à vivência do preconceito e da discriminação. (MINATEL; MATSUKURA, 2015).

Por outro lado, Fiaes (2010) numa pesquisa com 5 crianças autistas com idade entre 4 e 9 anos, avaliou os padrões de brincadeiras espontâneas de crianças autistas em escola de educação regular e especial. No resultado deste estudo, observou o papel ativo das crianças autistas na iniciação de episódios de interação, principalmente quando eles aconteciam com seus pares. Observou que o tempo disponível para brincar, tipo de brinquedo e material humano são fatores que interferem na expressão da brincadeira e nas interações sociais. Sugeriu, ainda, que crianças autistas participam de maneira ativa da brincadeira, interagindo com pares e adultos. "Este trabalho traz uma mudança de visão sobre as possibilidades da criança autista, não apenas como alvos de intervenções, mas também como parceiras no processo de socialização e como sujeitos brincantes" (FIAES, 2010, s.d). Também, poderá contribuir com o educador na medida em que ele compreender que;

[...] ao entrar na cultura, a criança não apenas toma algo dela, adquire algo, incute em si algo de fora, mas também a própria cultura reelabora todo o comportamento natural da criança e refaz de modo novo todo o curso do desenvolvimento. A distinção de dois planos de desenvolvimento no comportamento (o natural e o 
cultural) torna-se o ponto de partida para uma nova teoria da educação. (VIGOTSKI, 2011, p. 866).

Há evidências de que as crianças autistas não vivem em um mundo próprio e particular como foi difundido durante muito tempo. Ao contrário, elas são capazes de socializar, de observar as tarefas de seus colegas e demonstram interesse por temas vistos nos meios de comunicação de maneira semelhante às crianças com desenvolvimento típico (FIAES, 2010). Esses achados corroboram a ideia de Vygotski, (1989) de que a educação das crianças com o desenvolvimento diferenciado do considerado normal deve ser baseada na ideia de que existem possibilidades de compensação para ultrapassar limitações que precisam ser incluídas na prática educativa e que devem ser direcionadas para suas consequências sociais.

O estudo de Fiaes (2010) sobre a brincadeira espontânea de crianças autistas aponta que elas brincam mais quando têm oportunidade para isso, e que - se convidado pelos seus pares -aumenta a probabilidade de brincar. Também observou que:

Uma atenção maior sobre as interações ao longo dos registros nos fez refletir sobre o
papel ativo das crianças na iniciação de episódios de interação e na emissão de
comportamentos de cuidado. Curiosamente as crianças autistas foram as que mais
iniciaram interações. Tal fato pode levar a uma mudança de visão sobre as
possibilidades dessas crianças, para serem vistas não apenas como alvos de
intervenções e de ajuda, mas também como parceiras no processo de socialização e
como sujeitos brincantes. (FIAES, 2010, p. 152).

A discussão realizada por Fiaes (2010), Martins e Góes (2013) Silva, Dias, Martins e Tenório (2011), Lima e Fumes (2013) e do Vigotski (1989) possibilitam sustentar a ideia que o processo de desenvolvimento da criança com autismo percorre um caminho singular. Por isso, os mediadores no processo de ensino-aprendizagem devem possibilitar meios apropriados à sua estimulação, principalmente os voltados à sua interação social que, nesta análise, teve no brincar um elemento relevante.

Observa-se a brincadeira como uma prática social que é realizada também pela criança com autismo, e se o professor a colocar na posição de sujeito, poderá garantir seu lugar de participante da cultura. Assim, a brincadeira é uma possibilidade de desenvolvimento da criança nessa condição, sendo um instrumento estimulador de sua interação e inserção cultural e social. O brincar é fundamental para o desenvolvimento da criança, no que se refere aos aspectos do crescimento, da saúde e socialização, além de ser uma forma de o sujeito se comunicar consigo e com os outros.

A prática pedagógica que usa a brincadeira no processo de ensino-aprendizagem de alunos com transtornos do espectro autista favorece a interação social e a inclusão, 
possibilitando também, a partir das ideias de Carvalho (2010), a adequação da remoção de barreiras para a aprendizagem, devendo ser uma ação intencional educativa de qualquer educador que veja cada estudante como um cidadão com capacidades a serem desenvolvidas, o que traduz um papel político e pedagógico.

\section{CONSIDERAÇÕES FINAIS}

O processo de aprendizagem e desenvolvimento de crianças autistas é marcado por particularidades, sendo que o ato de brincar poderá influenciar a trajetória do seu desenvolvimento.Através da brincadeira a criança interage e se relaciona com outras pessoas, tendo a oportunidade para desenvolver a atenção, afetividade, memória, percepção, linguagem, fala e a sua expressão. No brincar, a criança emite emoções variadas, entra em contato consigo mesmo, explora o ambiente ao seu redor e cria relações entre o seu eu e o mundo.

No contexto de educação, o brincar não deve ser considerado apenas como uma forma de divertimento, pois possibilita à criança aprender e desenvolver as interações sociais. Por isso, a brincadeira deveria estar mais presente na prática educativa direcionada à crianças com o transtorno do espectro autista. Porém é preciso que o professor tenha orientação e uma capacitação para superação de barreiras no processo de inclusão. Embora o senso comum apregoe que crianças com autismo têm dificuldade em brincar, essa ideia não se sustenta e que os professores dispostos a tentar, poderão se surpreender com a participação dessas crianças.

O brincar como recurso educativo merece atenção e espaço no processo de ensinoaprendizagem. O professor que desenvolve sua ação pedagógica compreendendo que a aprendizagem e desenvolvimento também podem ocorrer com criança de "singularidade concreta/visível", ultrapassa os limites arraigados do processo educativo e demonstra que é possível ter uma prática de inclusão.

\section{REFERÊNCIAS}

ASSOCIAÇÃO AMERICANA DE PSIQUUIATRIA DSM- V. Manual diagnóstico e estatístico de transtornos mentais. Tradução Maria Inês Corrêa Nascimento et al., 5. ed. Porto Alegre, RS: Artmed, 2014.

BRASIL. Diretrizes Curriculares Nacionais para a Educação Básica: diversidade e inclusão. Brasília: CNE/MEC/SECADI, 2013. Disponível em:

$<$ http://portal.mec.gov.br/index.php?option=com_docman\&view=download\&alias=17212- 
diretrizes-curriculares-nacionais-para-educacao-basica-diversidade-e-inclusao2013\&category_slug=marco-2015-pdf\&Itemid=30192>. Acesso em: 10 fev. 2016. . Lei de Diretrizes e Bases da Educação Nacional. LDB nº 9394/1996.

BRASIL. Orientações para implementação da política de educação especial na perspectiva da educação inclusiva. Brasília: CNE/MEC/SECADI, 2015. Disponível em: $<$ http://portal.mec.gov.br/index.php?option=com_docman\&view=download\&alias=17237secadi-documento-subsidiario-2015\&Itemid=30192> . Acesso em: 10 fev. 2016.

CARVALHO, R. E. . Removendo barreiras para a aprendizagem: educação inclusiva. 10. ed. Porto Alegre, RS: Mediação, 2010.

CIANTELLI, A.P. C.; LEITE, L. P.; MARTINS, E. S. O. O transtorno global do desenvolvimento na educação inclusiva: escola comum ou escola especial? Práxis Educacional, v. 10, n. 16 p. 105-127 jan./jun. 2014. Disponível em: $<$ http://periodicos.uesb.br/index.php/praxis/article/viewFile/2892/2574>. Acesso em: 2 de ago. 2015.

CUNHA, E. Autismo e inclusão: psicopedagogia e práticas educativas na escola e na família. Rio de Janeiro RJ: Wak, 2014.

CUNHA, N. H. S. Brinquedoteca: um mergulho no brincar. 4. ed. São Paulo, SP: Aquariana, 2007.

DAGUANO, L. Q.; FANTACINI, R. A. F. O lúdico no universo autista. Linguagem Acadêmica, Batatais, v. 1, n. 2, p. 109-122, jul./dez. 2011. Disponível em:

$<$ claretianorc.com.br/download? caminho=upload/cms/revista $>$. Acesso em: 10 jun. de 2015.

DECLARAÇÃO DE SALAMANCA. Procedimentos-padrão das Nações Unidas para a Equalização de Oportunidades para Pessoas Portadoras de Deficiências. Resolução das Nações Unidas adotada em assembleia geral, Espanha, 1996.

FIAES, C. S. Espontaneidade, parcerias e influências do contexto em brincadeiras livres de crianças autistas. Dissertação (Mestrado em Psicologia) - UFBA, Salvador, 2010. Disponível em: <http://www.pospsi.ufba.br/Carla_Fiaes.pdf $>$ Acesso em: $<10$ de jun. de 2015.>

GUARESCHI, T.; ALVES, M. D.; NAUJORKS, M.I. Alunos com autismo na escola: problematizando as políticas públicas. In: X ANPED SUL, Florianópolis, outubro de 2014. Anais... Disponível em: http://xanpedsul.faed.udesc.br/arq pdf/791-0.pdf. Acesso em: 1 jan. 2015 .

LIMA, T. H. M.; FUMES, N. L. F. Crianças com autismo: possibilidades de ensino a partir do brincar. In: VIII ENCONTRO DA ASSOCIAÇÃO BRASILEIRA DE PESQUISADORES EM EDUCAÇÃO ESPECIAL, 2013, Londrina.

MARCHESI, À. Da linguagem da deficiência às escolas inclusivas. In: COLL, C.; MARCHESI, À.; PALACIOS, J. (Org.). Desenvolvimento psicológico e educação. 2. ed. Tradução de Fátima Murad. Porto Alegre: Artmed, 2010, p.15-30. V.3. 
MARINHO, E. A. R.; MERKLE, V. L. B. Um olhar sobre o autismo e sua especificação. In: IX CONGRESSO NACIONAL DE EDUCAÇÃO - EDUCARE. III ENCONTRO SUL BRASILEIRO PSICOPEDAGOGIA, PUCPR, 2009. Disponível em:

$<$ http://www.pucpr.br/eventos/educere/educere2009/anais/pdf/1913_1023.pdf. $>$. Acesso em: 2 ago. 2015.

MARTINS, A. D. F.; GÓES, M. C. R.. Um estudo sobre o brincar de crianças autistas na perspectiva histórico-cultural. Psicol. Esc. Educ., Maringá, v. 17, n. 1, p. 25-34, Jun. 2013 . Disponível em: <http://www.scielo.br/scielo.php?script=sci_arttext\&pid=S1413$85572013000100003 \& \operatorname{lng}=\mathrm{en} \& n \mathrm{~nm}=\mathrm{iso}>$. Acesso em: 2 ago. 2015.

MINATEL, M. M.; MATSUKURA, T. S. Familiares de crianças e adolescentes com autismo: percepções do contexto escolar. Revista Educação Especial, v. 28, n. 52, p. 429442, maio/ago, 2015. Disponível em: <http://www.ufsm.br/revistaeducacaoespecial $>$. Acesso em: 2 set. 2015.

OLIVEIRA, M. K. Vygotsky, aprendizado e desenvolvimento: um processo sócio-histórico. São Paulo, SP: Scipione, 1993. (Pensamento e ação no magistério).

PIAUILINO, J. D. Educando pessoas com autismo para conviver em sociedade. Araguaína: Ed. Santa Rita, 2008. SANCHES, I., TEODORO, A.. Da integração à inclusão escolar: cruzando perspectivas e conceitos. Revista Lusófona de Educação, América do Norte, 8, Jul. 2006. Disponível em:

$<\mathrm{http}$ ://revistas.ulusofona.pt/index.php/rleducacao/article/view/691/583>. Acesso em: 05 mar. 2016.

SILVA, A. D. P.; DIAS, G. R.; MARTINS, M. M.; TENÓRIO, C. A. Autismo: a utilização do brincar como forma de interação social. In: XIII JORNADA DE ENSINO, PESQUISA E EXTENSÃO - JEPEX, 2013 - UFRPE: Recife.

VIGOTSKI, L. S. A defectologia e o estudo do desenvolvimento e da educação da criança anormal. Educ. Pesqui., São Paulo, v. 37, n. 4, p. 863-869, dez. 2011 . Disponível em: $<$ http://www.scielo.br/scielo.php?script=sci_arttext\&pid=S151797022011000400012\&lng=en\&nrm=iso>. Acesso em: 06 fev. 2016.

Obras completas. Tomocinco: fundamentos de defectologia. Havana: Editorial Pueblo y Educación, 1989.

VIGOTSKY, L. S. A formação social da mente. São Paulo, SP: Martins Fontes, 1984. Construção do pensamento e da linguagem. São Paulo, SP: Martins Fontes, 2003. 